\title{
Monoclonal Antibody 2A11
}

National Cancer Institute

\section{Source}

National Cancer Institute. Monoclonal Antibody 2A11. NCI Thesaurus. Code C29211.

A recombinant, murine monoclonal antibody directed against gastrin-releasing peptide, one of a number of bombesin-like peptides (BLP). Tumor cells, such as small cell lung cancer (SCLC) cells, express and secrete BLP that activate specific cell growth-promoting receptors. Monoclonal antibody $2 \mathrm{~A} 11$ has been shown to decrease the growth of SCLC cells in vitro and in animal models. ( $\mathrm{NClO4})$ 